\title{
Index-based optimal DG allocation for voltage quality improvement in an unbalanced network
}

\author{
Ahmadreza Eslami * \\ Department of Electrical and Computer Engineering, Isfahan University of Technology Isfahan, Iran.
}

Global Journal of Engineering and Technology Advances, 2021, 06(02), 090-103

Publication history: Received on 10 January 2021; revised on 12 February 2021; accepted on 14 February 2021

Article DOI: https://doi.org/10.30574/gjeta.2021.6.2.0020

\begin{abstract}
Voltage quality is a one of the major concerns in distribution systems. Distributed Generations (DGs) have the potential to improve voltage quality, if optimally planned and operated. Considering the problem of DG siting and sizing, this paper aims at integrating technical factors, particularly voltage quality, in planning of DGs. Hence, a methodology is proposed which optimizes voltage quality in the presence of DGs and can be used as one of the objectives in a multiobjective problem or as an intermediate stage in usual DG planning. Modified voltage quality indices are proposed which consider factors including voltage profile, voltage variation due to DG disconnection, voltage regulation and voltage unbalance. The indices are defined in such a manner suitable for three-phase unbalanced networks. The system voltage quality is assessed by a new comprehensive voltage quality index. By applying this index, the DGs locating and penetration problem is formulated to improve system voltage quality. The method is tested on IEEE 13-bus feeder which is an inherently unbalanced network.
\end{abstract}

Keywords: Voltage quality; Distributed generation planning; Multi-objective voltage index; Voltage profile; Voltage unbalance

\section{Introduction}

Distribution networks are facing significant technical constraints and uncertainties due to the integration of uncertain generations such as solar and wind and modern sensitive loads. In this regard, power quality has always been a concern for system planners and operators. Distribution network operators (DNOs) need to improve the quality of service, integrate high penetration of distributed generations (DGs), forecast energy flow and improve efficiency, all while maintaining stable voltage at an acceptable level under all loading and operating conditions [1]. DGs have the potential to be added to modern distribution systems and improve system performance from voltage quality point of view. On the other hand, uncoordinated and badly planned DGs might decrease system voltage quality and technical constraints, especially those related to voltage, could limit the penetration of DGs in distribution systems. Therefore, voltage quality consideration is a necessity in today's power systems. Furthermore, DGs as an interesting alternative have revealed their potential in technical support of electrical networks competing neck and neck with traditional resources and network expansion alternatives. Accordingly, presenting methodologies which provide the option of voltage quality evaluation and improvement is useful in DG planning and scheduling programs and has been pursued as the aim of this paper. Voltage quality improvement can find its place in DG planning programs either as an intermediate stage or as one of the objectives in multi-objective planning programs. This trend can provide the planner a chance to choose a trade-off solution from a set of economically planned solutions by a criterion that maximizes system voltage quality.

In literature, DGs planning programs considered economic, technical, environmental and combination of these three objectives. Most works on DG planning have considered economic cost objective function [2-7] or a combination of

\footnotetext{
* Corresponding author: Ahmadreza Eslami; Email: ahmadreza.eslami.0905@gmail.com

Department of Electrical and Computer Engineering, Isfahan University of Technology Isfahan, Iran. 
economic, technical and environmental objective functions [8-11]. The model of [2] provided that the investment and operating cost of DGs along with loss cost were minimized. Refs [3] and [7] considered the uncertainty attributed to DGs performance in planning problem. Optimization of the cost of loss, reliability, imported power from upstream alongside network investment was carried out in [3] while microturbines and wind turbines were considered in [7] to maximize the profit over a long-term period. In terms of combined objective functions, expected cost and risk corresponded to different energy carriers were reduced in [8] in the presence of energy price uncertainty. In [9], both planning and operation stages were accounted to maximize the DG penetration level and minimize DG curtailment subject to economic and technical constraints. Authors in [10] integrated DGs, battery storages and DSTATCOMs in a multi-objective optimization problem to improve network profit-cost ratio, voltage profile, environmental index and reliability. In [11], the objectives including loss reduction, voltage improvement, system stability and yearly economic saving have been dealt with in DG planning problem in the presence of uncertainty.

Bunch of references considered technical objective functions for the aim of DG planning. Muttaqi et al. [12] presented an algebraic framework to site, size and optimize operation of DGs in order to achieve the required network voltage level. The uncertainty associated with loads was also considered. Khanbabapour and Golshan proposed an approach for synchronous DG planning to optimize several objectives such as energy loss, investment deferral, voltage variation and protection speed. In [14], a methodology was proposed for optimal allocation of DG units in distribution system to minimize annual energy loss. In [15], a method that employed harmony search algorithm with differential operator was proposed to optimally install multiple DG units in distribution system with the objective of minimizing active power loss and improving voltage profile. Yammani et al. [16] proposed a hybrid optimization algorithm for optimal placement and sizing of the DGs. Bus voltage profile improvement, line flow capacity, and active and reactive power loss minimization were considered as multi-objectives to be optimized under distribution load enhancement. Kyu-Ho Kim et al. [17] presented a method to determine the locations and sizes of DGs for loss reduction and voltage profile enhancement in distribution systems. Carpinelli et al. [18] proposed a multi-objective program which solved the problem of maximizing the network performance by optimizing some power quality indicators, like voltage quality and harmonic distortion and minimizing the network costs. Ochoa et al. [19] presented a multi-objective performance index for distribution network with DG which considered a wide range of technical issues such as voltage, capacity of conductors and power loss. This index could be used in planning DGs from technical point of view. Singh et al. [20] presented a multi-objective index-based size and location determination of DG in distribution systems with different load models. The multi-objective function was formed by using various indices reported in [19]. Soroudi et al. [21] proposed a probabilistic dynamic model for multi-objective DG planning. The first objective was the minimization of total cost and the second objective was defined as the minimization of technical risk, considering the probability of violation of the safe operating technical limits.

Some technical constraints might be faced by DG project and limit the penetration of DG in the system. Therefore, evaluating technical issues, like voltage quality, is becoming increasingly important in DG planning programs. Keane et al. [22] proposed a methodology using linear programming to determine the optimal allocation of DG with respect to technical constraints. The objective was to maximize generation subject to those constraints. In [23], an optimization problem was proposed to determine the maximum DG penetration level by optimally selecting types, locations and sizes of utility owned DG units. It was concluded that DG penetration level could be limited by harmonic distortion and protection coordination constraints.

DG units can affect all parameters of system voltage. Voltage profile is reported to improve in the presence of DG if proper planning is performed prior to installation [24]. Voltage unbalance is also influenced and may be worsen or mitigated due to DG unit location and supplied power in each phase. In this paper, an optimization problem is formulated which determines the optimal DG location and penetration to improve system voltage quality. Voltage quality is evaluated based on a multi-objective voltage index (MVI) which forms the objective function of the optimization problem. MVI takes into account voltage profile, voltage unbalance, voltage regulation and voltage variation due to source disconnection. For each steady state voltage criterion, a three-phase system index is introduced and MVI is the weighted average of these indices.

The methodology explained above, could be used as an intermediate voltage quality stage in usual DG planning or as one of the objectives in a multi-objective DG planning program. Besides, it can be applied to a system with sensitive loads and consumers that require high voltage quality for which voltage issues are of higher priority in comparison with economical ones. The merits of the proposed methods in comparison to the literature are listed below:

- The modified indices proposed for voltage quality evaluation in an unbalanced network can provide a useful tool for any technical evaluation in the network. 
- To the author's best of knowledge, this is the first time that voltage quality indices such as voltage unbalance are considered in DG planning.

The remainder of the paper is organized as follows. Section 2 evaluates DG impacts on voltage quality. The modified voltage quality indices are presented in section 3 and the optimization problem formulated in section 4 . The power system under study and result and discussion are presented in sections 5 and 6, respectively. Finally, section 7 presents conclusions.

\section{Dg impacts on voltage quality}

\subsection{Steady State Voltage Profile}

Steady state voltage is amongst the most important power quality aspect for customers. Keeping steady state voltage levels with permissible limits is important because of [1]:

- $\quad$ Providing for end customer equipment long life, performance and efficiency

- Safety, particularly due to overheating/fire caused by voltage or current stresses

Generally, the presence of DGs could improve the system steady state voltage profile. However, system voltages might violate the permissible bounds due to badly planned and operated DGs and this fact could limit the penetration of DG in the system. For example, overvoltage caused by DG in low demand periods might restrict the penetration limit.

Table 1 Maximum Allowable Number of DGs Considering Steady State Voltage Profile Violation [25].

\begin{tabular}{|l|l|l|}
\hline generator type & $\begin{array}{l}\text { maximum number of } \\
\text { generators }\end{array}$ & no problem \\
\hline $\begin{array}{l}\text { constant voltage synchronous } \\
\text { generator }\end{array}$ & 6 & $\begin{array}{l}\text { superior limit violation during } \\
\text { minimum demand }\end{array}$ \\
\hline $\begin{array}{l}\text { constant power factor } \\
\text { synchronous generator }\end{array}$ & 2 & $\begin{array}{l}\text { inferior limit violation during } \\
\text { maximum demand }\end{array}$ \\
\hline induction generator & 5 & \multicolumn{2}{|l}{} \\
\hline
\end{tabular}

Table 1 shows the result of an evaluation performed in [25], which considers the maximum number of synchronous/induction 5 MW DGs in different mode of operation which could be added to a specific bus of the system without voltage violation from permissible limits. It is seen that the voltage permissible bounds limit DG penetration level in constant power factor synchronous and induction generator. Therefore, a precise evaluation of voltage quality seems necessary prior to DG installation.

\subsection{Voltage Unbalance}

Voltage unbalance is one of the prevalent power quality problems in distribution networks. Voltage unbalance can be attributed to factors such as: the unsymmetrical impedance of transmission and distribution lines, unbalanced or unstable power utilities, unbalanced three phase loads, uneven spread of single phase loads across the three phases and weak rural power electric systems with long transmission lines [18].A mild unbalance in the voltage could lead to a large current unbalance which adversely affects power system equipment such as induction motors, power electronic devices and machine drives. Under unbalanced condition, the power system will incur more losses and heating effects and would be less stable. [21].

The adverse effects of unbalanced voltages on induction motors stem from the fact that the unbalanced voltage breaks down into positive, negative and zero sequence components. However, the zero component in motors is typically zero as they are mostly connected delta or ungrounded wye. Therefore, the unbalanced motor voltage contains positive and negative sequence components which have opposing phase sequences, i.e., " $a b c$ " and " $a c b$ ", respectively. Consequently, two opposing torques are produced, one of which desired and the other one opposing to the beneficial one leading to a reduction in the net torque and speed. This can cause torque and speed pulsation and increase motor noise. In addition, the negative sequence component in the unbalanced voltages generates large negative sequence currents due to the low 
negative sequence impedance, which increases the machine losses and temperatures. At normal operating speeds, unbalanced voltages cause the line currents to be unbalanced in the order of 6 to 10 times the voltage unbalance. Overall, the net effect of the voltage unbalance is reduced efficiency and decreased life of the motor [21].

Figure (1) shows the recommended derating for motors as a function of percent phase-voltage unbalance recommended by NEMA standard MG 1-1993 [26]. According to the figure, the rated horsepower of the motor should be multiplied by a derating factor based upon the degree of voltage unbalance.

In [27], an investigation of the effects of DG on voltage unbalance was done which concluded that voltage unbalance was improved by adding and increasing the size of DG. However, this result is only valid for the case study of reference [27] and could not be generalized. In [28], the effect of a cogeneration plant on the system unbalance of a three phase fourwire system has been evaluated and it was concluded the electric power generation of a cogeneration might worsen the voltage and current imbalance of distribution system, especially when large amount of power had been injected to the utility network. Consequently, the confirmed fact is that DG presence surely affects the system voltage unbalance and these effects are worth to be evaluated prior to installation in DG planning programs.

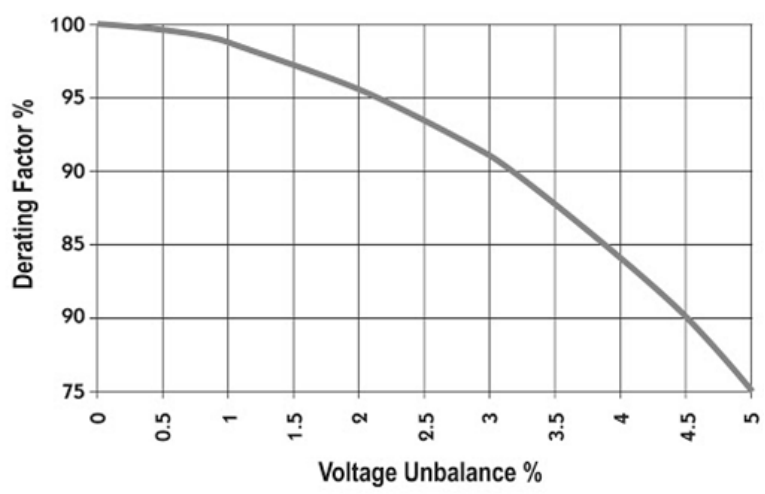

Figure 1 Derating factor for motors operating with phase voltage unbalance [26]

\section{Voltage quality indices considering DG presence}

\subsection{Steady State Voltage Profile Index}

Steady state voltage profile is one the major characteristic of voltage quality affected by DG presence. The system buses voltage is desirable to stand near the nominal voltage. In [19], voltage profile index (VPI) is introduced as follows.

$$
V P I=1-\max \left(\frac{\bar{U}_{\text {nom }}-\bar{U}_{\emptyset i}}{\bar{U}_{\text {nom }}}\right)_{i=1}^{n_{b}}
$$

Where $\varnothing$ is the phases $a, b$ and $c$; $\bar{U}_{n o m}$ is the nominal voltage of the system, $\bar{U}_{\emptyset i}$ is the phase øth voltage magnitude of the $i$ th bus and $n_{b}$ is the number of buses. VPI is defined in a manner that it is desired to get as close as possible to unity.

\subsection{Voltage Variation Index Due to DG disconnection}

One of the important issues of voltage quality is the variation of bus voltages due to DG disconnection. This fact is important because of the limited response of voltage controller in the system. It is desirable for the distributed network operator (DNO) that these variations are as low as possible. In [25], voltage variation index due to DG connection was introduced for a balanced system which considered only one phase in calculation. Therefore, for an unbalanced system, this index needs modification. One of the purposes of this study is to size and site DG to improve voltage unbalance and that system voltages are going to be more balanced. Hence, based on the positive sequence voltages, the modified voltage variation index (VVI) is proposed as follows.

$$
V V I=1-\frac{1}{n_{b}-1} \sum_{i=2}^{n_{b}}\left|U_{i, D G}^{+}-U_{i, N D G}^{+}\right|
$$


Where $U_{i, D G}^{+}$and $U_{i, N D G}^{+}$are the positive sequence magnitudes of voltage of $i$ th bus in the presence of DG and without DG, respectively. VVI is desired to be around unity which means system voltages vary so little due to DG disconnection. Slack bus is not considered in calculating VVI. This is because slack bus is assumed to be connected to a strong upstream network whose voltage is not affected by DG presence.

\subsection{Voltage Regulation Index}

Another important issue related to steady-state voltage is the regulation characteristic of the network, i.e., how much the bus voltages change between maximum and minimum demand cases. It is desirable that the bus voltages change as little as possible during load variations. In [25], voltage regulation index is defined for a balanced system which needs modification for use in an unbalanced system. Again, the modified voltage regulation index (VRI) is proposed based on positive sequence voltage as follows.

$$
V R I=1-\frac{1}{n_{b}-1} \sum_{i=2}^{n_{b}}\left|U_{i, \text { max }}^{+}-U_{i, \text { min }}^{+}\right|
$$

Where $U_{i, \max }^{+}$and $U_{i, \min }^{+}$are the positive sequence magnitudes of voltage of $i t h$ bus during maximum and minimum demands, respectively. VRI is desired to be around unity which means system voltages vary so little between maximum and minimum demand periods.

\subsection{Voltage Unbalance Index}

The International Electrotechnical Commission (IEC) defines voltage unbalance factor of an unbalanced voltage phasor based on positive and negative sequence as follows.

$$
V U F=\frac{U^{-}}{U^{+}}
$$

Where $U^{+}$and $U^{-}$are the positive and negative sequence voltage magnitudes. Eq. (4) gives a good definition of voltage unbalance for the evaluation of this paper. In calculating sequence component not only the voltage magnitudes but also the angles of voltages are considered. It is worth mentioning that zero sequence component is not considered in (4). This assumption is acceptable. Because according to section 2 explanation, mostly the damage due to voltage unbalance in induction motors as a main load type in the system, is caused by negative sequence component. Moreover, in some types of transformer, zero sequence is omitted from line component which reduce the importance of zero sequence component in voltage unbalance analysis.

Eq. (4) is defined for one bus of the system and proposing a system index which represents the system voltage unbalance is necessary for the evaluation of this phenomenon. Therefore, the Voltage Unbalance Index (VUI) is proposed as follows.

$$
V U I=1-\max _{1}^{n_{b}}\left(V U F_{i}\right)
$$

where $V U F_{i}$ is the voltage unbalance factor of $i$ th bus. $V U I$ is desired to be around unity which means the harmful negative sequence voltage component is negligible and system is in a good shape from voltage unbalance point of view.

\subsection{Multi-objective Voltage Index}

Each of the steady state voltage indices introduced before, considers one specific aspect of steady state voltage quality, separately and for simultaneous consideration of these factors, a system index for voltage quality seems necessary. Accordingly, this comprehensive index can be used in system planning programs and technical evaluations. The multiobjective voltage index $(M V I)$ is proposed as the weighted average of the previously proposed voltage indices as follows.

$$
\begin{gathered}
M V I=\sigma_{V P I} \times V P I+\sigma_{V V I} \times V V I+\sigma_{V R I} \times V R I+\sigma_{V U I} \times V U I \\
\sigma_{V P I}+\sigma_{V V I}+\sigma_{V R I}+\sigma_{V U I}=1 \quad \sigma \in[0,1]
\end{gathered}
$$

All these indices are in the range of zero to unity and MVI will be in the same range, consequently. This index is desirable to be around unity which represents a perfect steady state voltage quality of the system. The coefficients $\sigma$ should be chosen based on technical priorities and the judgment of system planners prior to DG installation. 


\section{Optimal location and penetration of DGs for voltage quality improvement}

In this section, different aspects of steady-state voltage are considered as the objective for optimal planning of DGs. The proposed steady-state voltage indices of section 3 are used as the objective function to attain the optimal location and probable capacity of DGs in view of voltage quality improvement. The results of the problems can be used:

- For DG planning when voltage quality is the concern of distribution system owner or operator due to existing a large number of sensitive and important loads. In this case, it is possible that long term economic benefits of DGs such as system losses and deferral investment be in second priority.

- As an intermediate stage in usual DG planning for determining candidate buses and maximum DG capacity in each candidate buses in view of affecting voltage quality.

\subsection{Objective Function}

The purpose of the problem is to maximize MVI which considers different aspects of steady state voltage quality. The control variables are active and reactive powers and location of DGs.

$$
\begin{aligned}
\text { Maximize } M V I= & \mathbf{F}\left(P_{D G_{n}}, Q_{D G_{n}}, b_{D G_{n}}, f_{D G_{n}}\right) \\
& n \in N_{D G}
\end{aligned}
$$

Where $P_{D G_{n}}, Q_{D G_{n}}$ and $b_{D G_{n}}$ are active power, reactive power, and location of the $n$th DG, respectively. $f_{D G_{n}}$ is the $n t h$ DG output power reduction factor (loading factor) in low load period and $N_{D G}$ the total number of DGs contributed in optimization program. MVI is a function of control variables. For a more desirable operation of DG, it is assumed that during the low load period, DG output power is decreased and set on a lower value than the nominal one.

\subsection{Equality Constraints}

The real and reactive power balance for each system bus must be satisfied. Because of the unbalance analysis of this paper, a three-phase unbalance load flow method is employed. Due to the radial nature of the system under evaluation, the iterative ladder method is selected for the load flow analysis [29] and [30]. This method employs forward and backward sweeps within which currents and voltages are calculated in each iteration, respectively. Convergence occurs when the calculated source voltage in the backward sweep corresponds to specified source voltage [30].

The equality constraints in each bus are the equations for real and reactive power balance based on load types. The equations are presented in [30] which are not mentioned here for brevity.

\subsection{Inequality Constraints}

\subsubsection{Steady-state Bus Voltage}

The bus voltages of the system are constrained to maximum and minimum permissible limits as in (9).

$$
U_{\text {down }} \leq U_{i} \leq U_{\text {up }_{i}} \quad i \in N
$$

where $U_{d o w n}$ and $U_{u p_{i}}$ refer to the downmost and upmost voltage limits at the $i$ th bus.

\subsubsection{Thermal Constraint}

Every cable in power system has a rated current limit which must not be violated as in (10).

$$
I_{i}<I_{i}^{\text {rated }} \quad i \in N_{L}
$$

where $I_{i}$ and $I_{i}^{\text {rated }}$ are current and rated limit of line $i$, respectively and $N_{L}$ is the set of lines of the system.

\subsubsection{DG Penetration Limit}

The penetration level of DGs is constrained to maximum permissible capacity as in (11).

$$
\sum_{n \in N_{D G}} P_{D G_{n}} \leq P_{D G}^{M a x}
$$




\subsubsection{DG Power Factor Limit}

DGs are desired to work in unity power factor to inject the maximum active power. However, as voltage quality is the objective of this paper, DG power factor has been permitted to sit in a range around unity so that reactive power capability of DGs is accounted for.

$$
P F_{D G} \geq P F_{\text {Min }}
$$

\subsubsection{Limit for DG Power Reduction Factor}

To have a better operation, the DG output power is reduced with the loading factor $f_{D G}$ in low load period. During the optimization procedure $f_{D G}$ is limited as follow.

$$
0.3 \leq f_{D G} \leq 1
$$

\subsection{Optimal DGs Planning Procedure}

The PSO algorithm is applied to solve the optimization problem. PSO is a heuristic algorithm which considers different populations in each iteration. The algorithm is initialized with a random first population. For every particle in the population, objective function is calculated, and optimization constraints are checked so that in case of any violation, those violations are added to the objective function using negative penalty factors. The local optimal ( $p b e s t$ ) and global optimal solutions (gbest) will be determined, and a new population will be produced. This procedure will be reiterated until the termination condition of the algorithm is satisfied. The corresponding details of PSO algorithm are presented in [23] and equations are as follows.

where

$$
\begin{gathered}
v_{i}^{k+1}=\omega v_{i}^{k}+c_{1} r_{1}\left(\text { pbest }_{i}^{k}-x_{i}^{k}\right)+c_{2} r_{2}\left(\text { gbest }_{i}^{k}-x_{i}^{k}\right) \\
x_{i}^{k+1}=x_{i}^{k}+v_{i}^{k+1}
\end{gathered}
$$

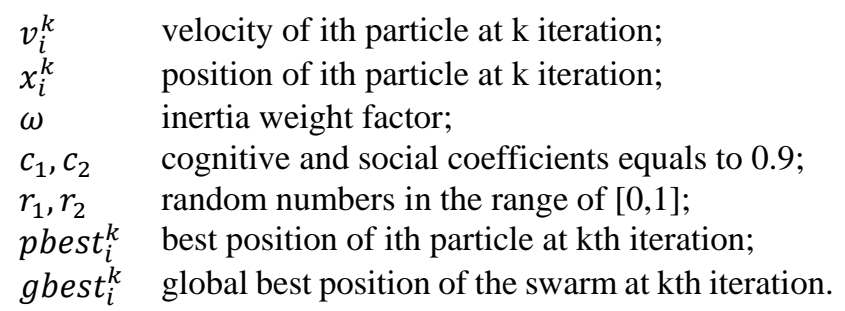

In order to have better balance between global exploration and local exploitation, the inertia weight $\omega$ is updated in each iteration as follows.

Where

$$
=\omega_{\max }-\frac{\omega_{\max }-\omega_{\min }}{i t e r_{\max }} \times k
$$

$$
\begin{array}{ll}
\omega_{\max } \text { and } \omega_{\min } & \text { minimum and maximum values of } \\
& \text { inertia weight set to be } 0.4 \text { and } 0.9, \\
& \text { respectively; } \\
& \text { maximum iteration number }
\end{array}
$$

Figure 2 shows the flowchart of the PSO based optimal DGs planning procedure. 


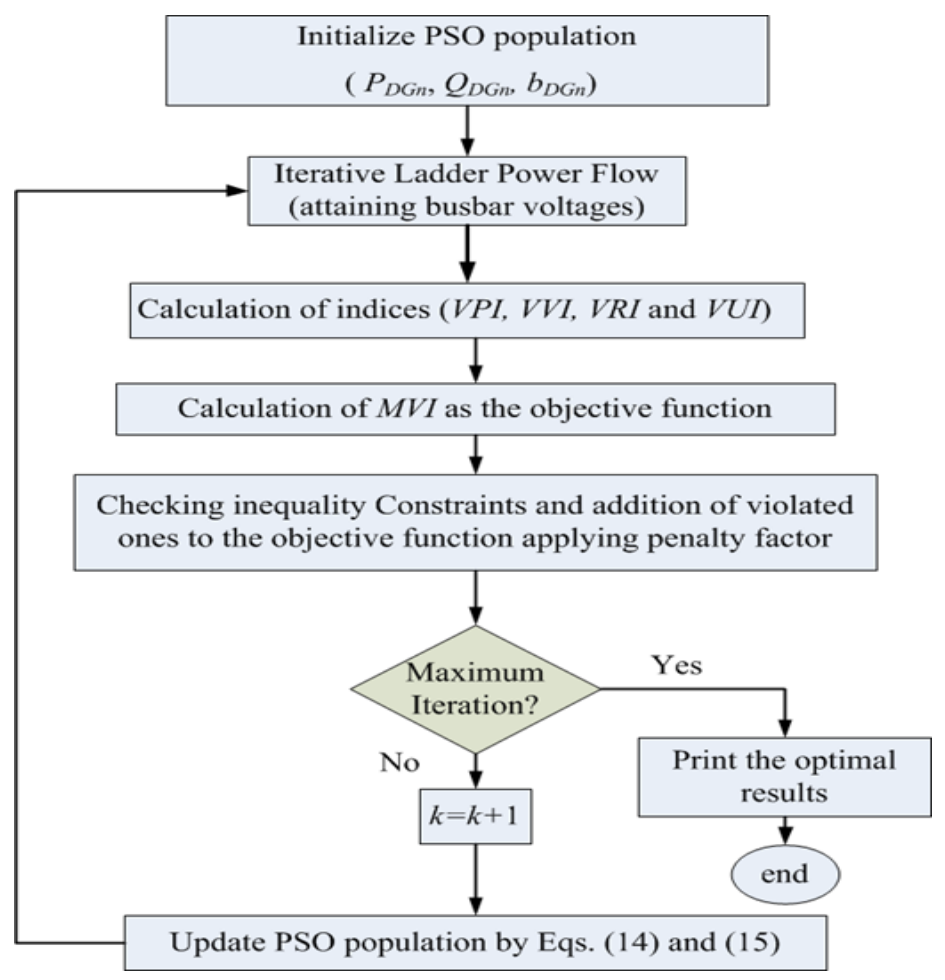

Figure 2 Flowchart of the PSO Based Optimal DGs Planning Procedure By velocity and position equations of PSO algorithm

\section{System under evaluation}

The proposed planning formulation was tested on the IEEE-13 bus feeder shown in figure (3) for which the data was obtained from IEEE test case archive for Distribution Feeders [31]. This unbalanced distribution feeder includes different system elements such as constant power, voltage and impedance loads, distributed loads, capacitors and transformers. System is operated at $4.16 \mathrm{kV}$ voltage level and connected to the upstream network via a $115 / 4.16 \mathrm{kV}$ delta-wye transformer. The total real and reactive loads of the system are $3466 \mathrm{MW}$ and $2084 \mathrm{MVAR}$, respectively which are distributed on three phases.

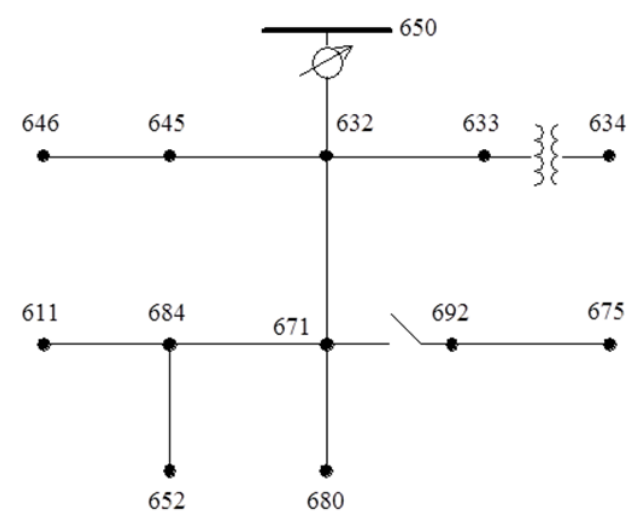

Figure 3 IEEE 13 bus Feeder

\section{Results and discussion}

\subsection{Cases under Evaluation}

Firstly, a specific case with a definite size and site of DG is considered without solving any optimization problem from voltage quality point of view. In the next step, optimal allocation of DG is considered in order to improve system voltage 
quality from a steady state lookout. Optimization problem is solved for cases of one and three DGs in power factor control mode and different coefficients of multi-objective index. Table 2 presents coefficients of $M V I$ for every case. For cases 1 to 4, indices VPI, VVI, VRI and VUI take unity coefficient with other coefficients set at zero, respectively. Case 5 is a general voltage case which considers different aspect of voltage quality by optimizing the multi-objective index. The index coefficients of case 5 are chosen in a manner that voltage profile and unbalance take the first and second priorities, respectively and voltage regulation and variation stand in the next priority level. The tap of distribution transformer is set at 1.04 and 1 for maximum and minimum load scenarios, respectively.

Because of the inherently unbalanced nature of the IEEE 13-bus feeder, some lines and buses only consist of one or two phases which leads to large amount of unbalance in these buses. For example, bus 652 is supplied only from a singlephase feeder to support a single-phase load. Therefore, only three-phase buses are considered in VUI calculation. Moreover, in calculating $V R I$, nominal system load and $50 \%$ of nominal load are taken as maximum and minimum load levels.

The maximum total capacity of DG is chosen $35 \%$ of system active load equal to $1200 \mathrm{~kW}$ which leads to maximum active capacity of $400 \mathrm{~kW}$ in each phase of the system. It is assumed that DG only injects power into present phases in the case of buses with one or two phases operated. Optimization problem is implemented and solved in MATLAB software.

Table 2 Values of Multi-objective Index Coefficients for Different Cases.

\begin{tabular}{|l|l|l|l|l|}
\hline Case & \multicolumn{1}{|c|}{$\boldsymbol{\sigma}_{V P I}$} & \multicolumn{1}{c|}{$\boldsymbol{\sigma}_{V V I}$} & \multicolumn{1}{c|}{$\boldsymbol{\sigma}_{V R I}$} & \multicolumn{1}{c|}{$\boldsymbol{\sigma}_{V U I}$} \\
\hline 1 & 1 & 0 & 0 & 0 \\
\hline 2 & 0 & 1 & 0 & 0 \\
\hline 3 & 0 & 0 & 1 & 0 \\
\hline 4 & 0 & 0 & 0 & 1 \\
\hline 5 & 0.4 & 0.15 & 0.15 & .3 \\
\hline
\end{tabular}

\subsection{A Specific Case from Voltage Quality lookout}

In this case, a DG with active power $400 \mathrm{~kW} /$ phase and reactive power $200 \mathrm{kVAR} /$ phase is allocated to bus 464 and the DG output power reduction factor is set at $f_{D G}=0.6$ for minimum load level scenario. The multi-objective index is calculated using coefficients of the last row of table 2. Table 3 presents the value of different indices without DG and in the presence of non-optimal DG in the system.

Table 3 Results for a specific DG case and without DG

\begin{tabular}{|l|l|l|l|l|l|}
\hline Case & \multicolumn{1}{|c|}{$\boldsymbol{V P I}$} & \multicolumn{1}{c|}{ VVI } & \multicolumn{1}{c|}{ VRI } & \multicolumn{1}{c|}{ VUI } & \multicolumn{1}{c|}{$\boldsymbol{M V I}$} \\
\hline With DG & 0.8869 & 1 & 0.9782 & 0.9629 & 0.9404 \\
\hline Without DG & 0.8980 & 0.9797 & 0.9855 & 0.9592 & 0.9418 \\
\hline
\end{tabular}

As shown in the table, indices have not improved much in the presence of DG and even VUI has worsened due to DG presence in bus 646. According to $M V I$, system voltage quality has not got significant improvement due to DG presence. In 13-bus feeder, the least loading of the system is assigned to phase $b$. Bus 646 only has phase $b$ and $c$ and DG injects power only in these phases. With the injection of this excess power, the load near DG location are supplied by DG and loading in further lines of phase $b$ from DG is even lowered which causes more unbalance in the system. Moreover, phase $a$ has the highest loading between phases which does not receive any generation from DG. Because of the DG active and reactive power injected in phases $b$ and $c$, the voltage magnitude of these phases is increased although no excess power is injected to phase $a$ which leads to no sufficient improvement in voltage profile.

\subsection{Optimal DG allocation based on voltage Quality}

DG sitting and sizing is performed for one and three DGs allocation cases. The maximum capacity of DG is $400 \mathrm{~kW} / \mathrm{phase}$. All DGs are operated in PQ mode and the power factor of DG, as one of the control variables, is set in the range of 0.85 lag to 0.85 lead. 


\subsubsection{One DG Allocation}

Table 4 shows the optimal capacity and location of one DG in PQ mode for different cases. In the presence of DG, voltage unbalance and accordingly current unbalance is mitigated. In 13-bus feeder, the total active load of phase $a, b$ and $c$ are 1158,973 and 1135kW, respectively. Due to DG power injection in phases $a$ and $c$ and supplying some part of loads in adjacent buses such as 652 and 611 by DG, the loading of upstream lines in these phases is reduced and consequently, less current unbalance leads to less voltage unbalance.

Table 4 Results for one DG optimal allocation in PQ mode

\begin{tabular}{|l|l|l|l|l|l|l|l|l|l|}
\hline Case & VPI & VVI & VRI & VUI & $M V I$ & $\begin{array}{l}P_{D G} / \boldsymbol{\varphi} \\
(\mathbf{k W})\end{array}$ & $\begin{array}{l}Q_{D G} / \boldsymbol{\varphi} \\
(\mathbf{k W})\end{array}$ & $\boldsymbol{b}_{\boldsymbol{D} G}$ & $f_{\boldsymbol{D} G}$ \\
\hline 1 & 0.9636 & 0.9704 & 0.9966 & 0.9907 & 0.9636 & 400 & 428 & 684 & 0.3 \\
\hline 2 & 0.9500 & 0.9795 & 0.9952 & 0.9831 & 0.9795 & 266 & 165 & 684 & 0.3 \\
\hline 3 & 0.9598 & 0.9732 & 0.9972 & 0.9885 & 0.9972 & 358 & 222 & 684 & 0.3 \\
\hline 4 & 0.9636 & 0.9704 & 0.9966 & 0.9907 & 0.9907 & 400 & 248 & 684 & 0.3 \\
\hline 5 & 0.9636 & 0.9704 & 0.9966 & 0.9907 & 0.9778 & 400 & 248 & 684 & 0.3 \\
\hline
\end{tabular}

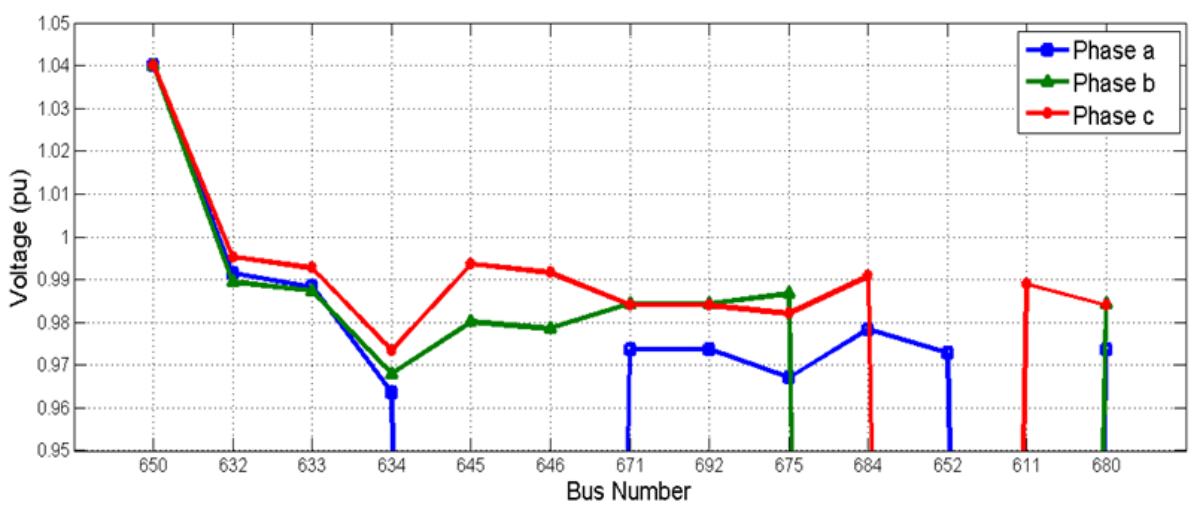

Figure 4 Voltage profile of three phases in the presence of optimal DG

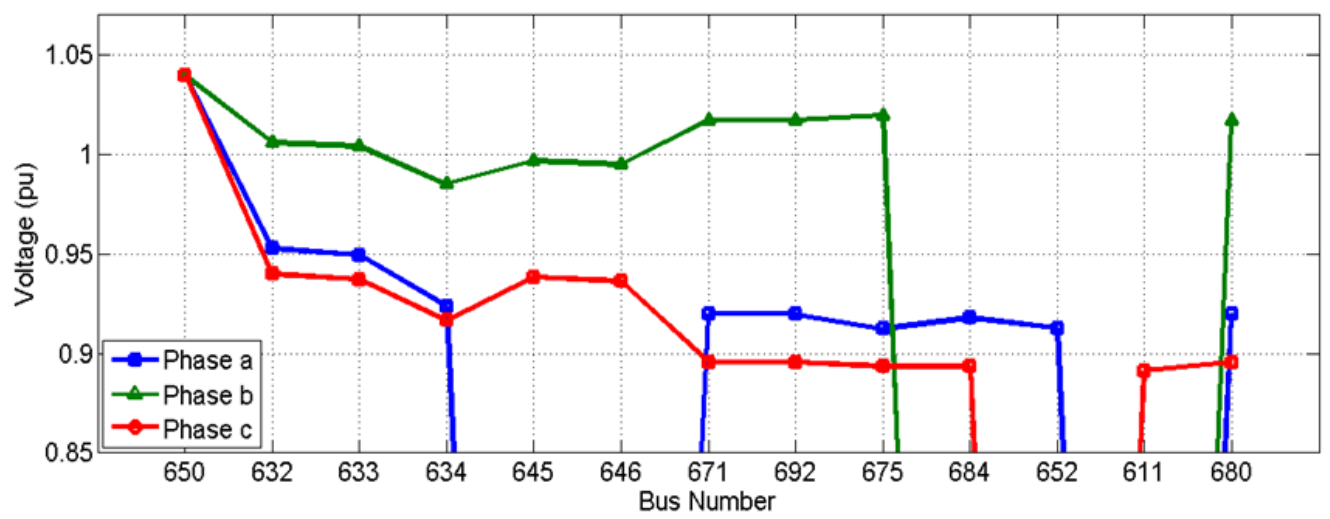

Figure 5 Voltage profile of three phases without DG

With power injection into phases $a$ and $c$, the voltage drop in these phases is mitigated and voltage profile is improved. As mentioned before, with tap of transformer on 1.04, the voltage of phase $b$ is also close to 1 pu. Therefore, with voltage of three phases close to unity, both indices of voltage profile and voltage unbalance are improved, and they are optimized in the same points. Hence, optimal DG allocations based on VPI and VUI lead to the same results. Moreover, because VPI and VUI take the highest coefficient values in case 5, the result of case 5 is also the same as cases with VPI 
and VUI as objective functions (cases 1 and 4). It is notable that although DG injects power only in phases $a$ and $c$, DG presence affects voltage of phase $b$. This is due to mutual impedances of lines between phases and delta connected loads.

In case two, VVI is taken as the objective function. Theoretically, if the capacity of DG is zero, this index stands on unity and there is no voltage variation due to DG disconnection. However, with optimization problem limits especially those related to voltage applied, the optimal active capacity of DG is set at $294 \mathrm{~kW}$ in bus 684 for problem limits satisfaction. In fact, DG power is chosen in a manner that VPI equals 0.95 which is the minimum requisite for voltage limits satisfaction. Therefore, in all DG allocation cases, $V V I$ is not much effective and changes according to steady state voltage limits. In all cases, VRI is set near unity and its variation range is not significant for different cases. This is because of considering the DG output power reduction factor $\left(f_{D G}\right)$ in control variables so that the index gets proper values by setting $f_{D G}$ for low load periods.

To get a better vision of DG optimal planning, the voltage profiles of system phases for case five in the presence of DG and without DG are presented in Figure 4 and Figure 5, respectively. If one phase does not exist for a bus, the voltage of the absent phase is set at zero. As seen from figures, the three-phase voltage profile has got close to unity and has been improved by the presence of DG. By reduction of differences between phase voltage magnitudes, voltage unbalance is also mitigated, somehow. It is notable that although optimal DG only injects power into phases $a$ and $c$, voltage of phase $b$ is also reduced and closer to $1 \mathrm{pu}$ in the presence of DG. This is caused by phase $a$ current reduction due to DG power injection. The current of phase $a$ lags voltage of phase $a$ in most buses but this current leads voltage of phase $b$. With voltage of phase $b$ as the reference, this leading current causes voltage increase in phase $b$ due to the mutual impedance between phases. In the absence of DG, the loading and accordingly the current of phase $a$ is higher and this current decreases noticeably in the presence of DG. Therefore, voltage of phase $b$ decreases in the presence of DG and get closer to unity.

Table 5 Results for Three DGs Optimal allocation in PQ mode

\begin{tabular}{|c|c|c|c|c|c|c|c|c|c|}
\hline Case & VPI & VVI & VRI & VUI & MVI & $P_{D G} / \varphi(k W)$ & $Q_{\mathrm{DG}} / \varphi(\mathrm{kW})$ & $\mathbf{b}_{\mathrm{DG}}$ & $f_{D G}$ \\
\hline \multirow{3}{*}{1} & \multirow{3}{*}{0.9650} & \multirow{3}{*}{0.9797} & \multirow{3}{*}{0.9935} & \multirow{3}{*}{0.9786} & \multirow{3}{*}{0.9650} & 137 & 85 & 684 & 0.3 \\
\hline & & & & & & 215 & 134 & 671 & 1 \\
\hline & & & & & & 47 & 29 & 692 & .51 \\
\hline \multirow{3}{*}{2} & \multirow{3}{*}{0.9500} & \multirow{3}{*}{0.9941} & \multirow{3}{*}{0.9946} & \multirow{3}{*}{0.9760} & \multirow{3}{*}{0.9941} & 127.5 & 34 & 684 & .38 \\
\hline & & & & & & 116 & 40 & 671 & 0.4 \\
\hline & & & & & & 127 & 79 & 692 & .56 \\
\hline \multirow{3}{*}{3} & \multirow{3}{*}{0.9601} & \multirow{3}{*}{0.9761} & \multirow{3}{*}{.9973} & \multirow{3}{*}{0.9870} & \multirow{3}{*}{0.9973} & 41 & 22 & 680 & 0.3 \\
\hline & & & & & & 320 & 199 & 675 & 0.3 \\
\hline & & & & & & 28 & -6 & 692 & 0.3 \\
\hline \multirow{3}{*}{4} & \multirow{3}{*}{0.9620} & \multirow{3}{*}{0.9714} & \multirow{3}{*}{0.9940} & \multirow{3}{*}{0.9907} & \multirow{3}{*}{0.9908} & 386 & 239 & 684 & .64 \\
\hline & & & & & & 13 & 8 & 611 & .36 \\
\hline & & & & & & - & - & - & - \\
\hline \multirow{3}{*}{5} & \multirow{3}{*}{0.9638} & \multirow{3}{*}{0.9834} & \multirow{3}{*}{0.9972} & \multirow{3}{*}{0.9880} & \multirow{3}{*}{0.9790} & 337 & 208 & 684 & 0.3 \\
\hline & & & & & & 63 & 39 & 671 & .66 \\
\hline & & & & & & - & - & - & - \\
\hline
\end{tabular}

\subsubsection{Three DGs allocation}

Table 5 shows the optimal results for three DGs allocation in PQ mode. In all cases, DG active capacity is set at maximum. In case 1 which is based on VPI, one-third of total capacity of DG is allocated to bus 684 and two-third of DG capacity is allocated to buses 692 and 671 which are connected to each other via a switch and are equipotential. It is notable that switch control strategy is not considered in planning program of DG and the switch is assumed closed, permanently. In IEEE 13-bus feeder, the power consumptions of phases $a$ and $c$ are approximately $200 \mathrm{~kW}$ more than power consumption of phase $b$. As seen from optimal planning result of case 1,137 kW of DG power is also injected only in phase $a$ and $c$ and the rest of DG power is allocated to buses 671 and 692 which have three phases under operation. VPI get a little improvement in three DGs scenario than on DG. 
In case 2, because the disconnection of the largest DG is considered, the program has chosen the DG capacity values close to each other. Moreover, the largest DG is allocated to bus 684 and injects the lowest power to the system so that its influence on voltage magnitudes is kept to the minimum and the two smaller DGs are responsible for the voltage limits satisfaction. The optimal value of $V R I$ in different cases does not vary much due to optimal setting of $f_{D G}$ and the variation range of this index is small. The results obtained for case 4, is similar to one DG scenario and the major portion of DG is allocated to bus 684 . For three DG allocation in case 5 , the results are similar to one DG scenario. In this case, by installing $60 \mathrm{~kW}$ DG in bus 671 and the rest in bus 684, VRI and VVI have taken a little bit more improvement which leads to more improvement in MVI. Accordingly, the system voltage quality is a little bit improved in three DG case than one DG.

\section{Conclusion}

In this paper, the system voltage quality in the presence of DG was evaluated and a methodology was proposed which could be used as an intermediate stage in DG planning programs or as the objective function of DG planning in systems with voltage quality priorities that are system with valuable and high-sensitive loads. The voltage quality factors including steady state voltage profile, voltage variation due to DG disconnection, voltage regulation between high and low load period and voltage unbalance were considered and DG siting and sizing were carried out based on proposed indices of voltage quality. The following conclusions could be taken from this study:

- DGs, if not properly planned and operated, not only do not improve voltage quality but also reduce voltage quality from some phenomena outlook. Or the obtained improvement may not be economical. Therefore, detailed technical and economic evaluation of DG allocation prior to installation seems necessary.

- DGs could improve system voltage profile, but the overvoltage caused in low load periods can limit DG capacity in the system. By including DG scheduling in planning (loading factor), this problem is handled somewhat.

- DGs, if properly planned, can mitigate current unbalance and consequently voltage unbalance, by balancing loading of system lines.

- Multi-objective voltage index $(M V I)$ is a useful tool in evaluating system voltage quality which could be used in voltage quality investigation of an operated system or in DG planning and technical comparison between several economical scenarios of DG allocation.

\section{Compliance with ethical standards}

\section{Acknowledgments}

The author would like to thank Professor Hamedani Golshan for his kind support during author's study at Isfahan University of Technology.

\section{References}

[1] Huet O, Grenard S, Devaux O, Carre O. Power Steering. IEEE Power Energy M. 2011; 9(5): 42-51.

[2] El-Khattam W, Hegazy YG, Salama MMA. An integrated distributed generation optimization model for distribution system planning. IEEE T Power Syst. 2005; 20(2): 1158-1165.

[3] Martins VF, Borges CLT. Active distribution network integrated planning incorporating distributed generation and load response uncertainties. IEEE T Power Syst. 2011; 26(4): 2164-2172.

[4] Soroudi A, Ehsan M, Caire R, Hadjsaid N. Hybrid immune-genetic algorithm method for benefit maximisation of distribution network operators and distributed generation owners in a deregulated environment. IET Gener Transm Dis. 2011; 5(9): 961-972.

[5] Wang DT, Ochoa LF, Harrison GP. DG impact on investment deferral: network planning and security of supply. IEEE T Power Syst. 2010; 25(2): 1134-1141.

[6] Zhao JH, Foster J, Dong ZY, Wong KP. Flexible transmission network planning considering distributed generation impacts, IEEE T Power Syst. 2011; 26(3): 1434-1443.

[7] Zhang C, Xu Y, Dong ZY. Probability-Weighted Robust Optimization for Distributed Generation Planning in Microgrids. IEEE T Power Syst. 2018; 33(6): 7042-7051. 
[8] Martínez Ceseña EA, Capuder T, Mancarella P. Flexible Distributed Multienergy Generation System Expansion Planning Under Uncertainty. IEEE T Smart Grid. 2016; 7(1): 348-357.

[9] Othman MM, Ahmed HMA, Ahmed MH, Salama MMA. A Techno-Economic Approach for Increasing the Connectivity of Photovoltaic Distributed Generators. IEEE T Sustain Energ. 2019; 11(3): 1848-1857.

[10] Roy Ghatak S, Sannigrahi S, Acharjee P. Multi-Objective Approach for Strategic Incorporation of Solar Energy Source, Battery Storage System, and DSTATCOM in a Smart Grid Environment. IEEE Syst J. 2019; 13(3): 30383049.

[11] Elkadeem MR, Abd Elaziz M, Ullah Z, Wang S, Sharshir SW. Optimal Planning of Renewable Energy-Integrated Distribution System Considering Uncertainties. IEEE Access. 2019; 7: 164887-164907.

[12] Muttaqi KM, Le ADT, Negnevitsky M, Ledwich G. An Algebraic Approach for Determination of DG Parameters to Support Voltage Profiles in Radial Distribution Networks. IEEE T Smart Grid. 2014; 5(3): 1351-1360.

[13] Khanbabapour S, Hamedani Golshan ME. Synchronous DG Planning for Simultaneous Improvement of Technical, Overcurrent, and Timely Anti-Islanding Protection Indices of the Network to Preserve Protection Coordination. IEEE T Power Deliver. 2017; 32(1): 474-483.

[14] Atwa YM, El-Saadany EF, Salama M, Seethapathy R. Optimal Renewable Resources Mix for Distribution System Energy Loss Minimization, IEEE T Power Syst. 2010; 25(1): 360-370.

[15] Kollu R, Rayapudi SR, Sadhu VLN. A Novel Method for Optimal Placement of Distributed Generation in Distribution Systems Using HSDO. Int T Electr Energy. 2014; 24(4): 547-561.

[16] Yammani C, Maheswarapu S, Matam SK. Optimal Placement and Sizing of Distributed Generations Using Shuffled Bat Algorithm with Future Load Enhancement. Int T Electr Energy. 2015; 26(2): 274-292.

[17] Kim KH, Song KB, Joo SK, Lee YJ, Kim JO. Multi-objective Distributed Generation Placement Using Fuzzy Goal Programming with Genetic Algorithm. Europ T Electr Power. 2008; 18(3): 217-230.

[18] Carpinelli G, Celli G, Mocci S, Pilo F, Russo A. Optimisation of embedded generation sizing and siting by using a double trade-off method. IEE Proc-C. 2005; 152(4): 503-513.

[19] Ochoa LF, Padilha-Feltrin A, Harrison GP. Evaluating distributed generation impacts with a multi-objective index. IEEE T Power Deliver. 2006; 21(3): 1452-1458.

[20] Singh D, Verma KS. Multiobjective Optimization for DG Planning with Load Models, IEEE T Power Syst. 2009; 24(1): 427-436.

[21] Soroudi A, Caire R, Hadjsaid N, Ehsan M. Probabilistic dynamic multi-objective model for renewable and nonrenewable distributed generation planning. IET Gener Transm Dis. 2011; 5(11): 1173-1182.

[22] Keane A, O'Malley M. Optimal Allocation of Embedded Generation on Distribution Networks. IEEE T Power Syst. $2005 ; 20(3): 1640-1646$

[23] Pandi VR, Zeineldin H, Xiao W. Determining optimal location and size of distributed generation resources considering harmonic and protection coordination limits. IEEE T Power Syst. 2012; 28(2): 1245-1254.

[24] Calderaro V, Milanovic JV, Kayikci M, Piccolo A. The impact of distributed synchronous generators on quality of electricity supply and transient stability of real distribution network. Elect Power Syst Res. 2009; 79(1): 134143.

[25] Freitas W, Vieira JCM, Morelato A, Da Silva LCP, Da Costa VF, Lemos FAB. Comparative analysis between synchronous and induction machines for distributed generation applications. IEEE T Power Syst. 2006; 21(1): 301-311.

[26] Nema. Motors and Generators, ed. American National Standard. 1993.

[27] Saidian A, Heidari M, Mirabbasi D. Improvement of voltage unbalance and voltage sag in radial distribution systems using DG, 5th IEEE Conf. Indus. Electron. App. (ICIEA). 2010; 835-839.

[28] Chen TH, Yang WC. Effects of a cogeneration plant on the system imbalance of a distribution feeder connected with it. Int J Elect Power Energ Syst. 2001; 23(5): 381-388.

[29] Cheng CS, Shirmohammadi D. A three-phase power flow method for real-time distribution system analysis. IEEE T Power Syst. 1995; 10(2): 671-679. 
[30] Khushalani S, Solanki JM, Schulz NN. Development of Three-Phase Unbalanced Power Flow Using PV and PQ Models for Distributed Generation and Study of the Impact of DG Models. IEEE T Power Syst. 2007; 22(3): 10191025.

[31] Christie R. Power Systems Test Case Archive, University of Washington, (C) 1993 [Cited 2019 Aug. 25] Available from: https://labs.ece.uw.edu/pstca/pf14/pg_tca14bus.htm 